\title{
TOLERÂNCIA DA CULTIVAR DE SOJA COODETEC 201 AOS HERBICIDAS INIBIDORES DE ALS ${ }^{1}$
}

\author{
ALDO MEROTTO JR ${ }^{2}$, RIBAS A. VIDAL ${ }^{3}$ e NILSON G. FLECK ${ }^{4}$
}

\section{RESUMO}

A obtenção de cultivares resistentes aos herbicidas possibilita o aumento da diversidade dos herbicidas utilizados seletivamente para o controle de plantas daninhas em uma determinada cultura. O aumento da disponibilidade destes herbicidas na cultura da soja pode proporcionar maior facilidade no controle de plantas daninhas de difícil eliminação, de espécies com características biológicas semelhantes à cultura $\mathrm{e}$ de plantas daninhas resistentes aos herbicidas. $\mathrm{O}$ objetivo deste trabalho foi avaliar a resistência cruzada da cultivar COODETEC 201 a três herbicidas inibidores da ALS, não seletivos para a cultura da soja. O experimento foi realizado em casa de vegetação através da semeadura em vasos, o qual foi disposto em delineamento completamente casualizado em arranjo fatorial. Os tratamentos constaram das cultivares de soja COODETEC 201 e OCEPAR 14 e dos herbicidas imazapyr, metsulfuron e nicosulfuron, aplicados em cinco doses. A aplicação destes produtos foi realizada 30 dias após a emergência, quando as plantas de soja estavam no estádio V4. A área foliar e a fitoxicidade aos 14 e 35 dias após a aplicação do herbicida metsulfuron foram menos afetadas na cultivar COODETEC 201 do que na OCEPAR 14. A determinação da restrição do crescimento das plantas em função da matéria seca das plantas demonstrou que as duas cultivares são igualmente sensíveis ao herbicida imazapyr. A cultivar COODETEC 201 apresentou maior tolerância aos herbicidas metsulfuron e nicosulfuron, sendo 10,25 e 3,25 vezes, respectivamente, mais resistente do que a cultivar OCEPAR 14.

Palavras chave: Resistência aos herbicidas, seletividade, metsulfuron, imazapyr, nicosulfuron.

\section{ABSTRACT}

\section{Tolerance of the soybean cultivar Coodetec 201 to ALS inhibitor herbicides}

Herbicide resistant crops can increase the availability of herbicides for selective use in soybean, can provide weed control of tolerant weed species, weed with identical biological characteristics to the crop, and resitant weeds to herbicides. The objective of this research was to evaluate the cross resitance in the soybean cultivar Coodetec 201 to three ALS inhibitor herbicides not selective to this crop. The trial was conducted in greenhouse, in a completely randomized design in factorial arrangemant. The treatments consisted of soybean cultivars Coodetec 201 and Ocepar 14, and the herbicides imazapyr, metsulfuron and nicosulfuron at five rates each. The herbicides were sprayed 30 days after soybean emergence, in the fenological stage V4. The leaf area and injury

\footnotetext{
${ }_{2}^{1}$ Recebido para publicação em 08/04/99 e na forma revisada em 03/08/99.

2 Engenheiro Agrônomo, M. Sc. Prof. do Depto. de Plantas de Lavoura. Faculdade de Agronomia/UFRGS. C.P. 776, CEP: 91501-970, Porto Alegre/RS. E-mail: merotto@ vortex.ufrgs.br. Autor para correspondência.

${ }^{3}$ Engenheiro Agrônomo, Ph D. Prof. do Depto. de Plantas de Lavoura. Faculdade de Agronomia/UFRGS, Porto Alegre/RS. Bolsista do CNPq.

${ }^{4}$ Engenheiro Agrônomo, Ph D. Pesquisador Associado. Depto. de Plantas de Lavoura. Faculdade de Agronomia/UFRGS, Porto Alegre/RS. Bolsista do CNPq.
} 
14 and 35 days after treatments with metsulfuron were smaller in Coodetec 201 than in Ocepar 14. Both cultivars were suscetibible to imazapyr. The cultivar Coodetec 201 was 10,25 and 3,25 times

\section{INTRODUÇÃO}

O desenvolvimento de novos herbicidas é tradicionalmente realizado através da triagem de várias moléculas ou de alterações em compostos de atividade conhecida. Atualmente, a disponibilização de produtos para uma determinada cultura pode ser feita através da incorporação de novos mecanismos de seletividade em culturas normalmente sensíveis a estes herbicidas. As culturas resistentes aos herbicidas (CRH) são o mais recente refinamento tecnológico para o controle químico de plantas daninhas (Radosevich et al., 1992). O início do desenvolvimento das $\mathrm{CRH}$ aconteceu na década de 80 (Simpson \& Stoller, 1996) e possuiu grande impulso com o desenvolvimento de cultivares de canola resistente aos herbicidas triazinas, o que possibilitou o controle de plantas daninhas crucíferas nesta cultura (Kishore et al, 1992). Atualmente, várias culturas possuem incorporados genótipos resistentes aos herbicidas tais como: alface, algodão, arroz, canola, fumo, gramados, milho, soja, tomate e trigo (Cole, 1994; Simpson \& Stoller, 1996). A forma de obtenção das CRH baseia-se no uso de compostos que promovem mutação, sendo realizado posteriormente a seleção dos individuos mutantes através do uso do herbicida que se deseja incorporar resistência à cultura (Sebastian et al., 1989; Wright \& Penner, 1998). As CRH também podem ser obtidas através do isolamento e introdução de genes que codificam enzimas detoxificadoras ou insensíveis aos herbicidas (Cole, 1994; Saari \& Mauvais, 1996).

As CRH podem ser utilizadas em diversas situações. Duke (1996) e Wilcut et al. (1996) apontam um grande potencial de uso em culturas como algodão, por exemplo, que dispõem de um pequeno número de herbicidas seletivos, principalmente de pós emergência. Também, more tolerant to metsulfuron and nicosulfuron, respectivety, than Ocepar 14.

Key words: Herbicide resistance, selectivity, metsulfuron, imazapyr, nicosulfuron.

descreve-se que através das CRH amplia-se a possibilidade de uso de altas doses de herbicidas isolados (Simpson \& Stoller, 1996) ou em misturas (Wilcut et al., 1996), que assim proporcionam melhores níveis de controle, principalmente em plantas daninhas de difícil eliminação. Wright \& Penner (1998) e Krausz et al. (1997) referem que a utilização de herbicidas com grande persistência pode se tornar viável em rotações de cultura com a utilização de $\mathrm{CRH}$. Ainda, o controle de plantas daninhas de espécies botanicamente semelhantes à cultura pode se tornar mais eficiente através das CRH (Vidal, 1997). O manejo de áreas com plantas daninhas resistentes aos herbicidas também ganha mais uma forma de controle, pois amplia-se a possibilidade de utilização de herbicidas com diferentes mecanismos de ação e espectro de controle de ervas.

A maioria das $\mathrm{CRH}$ obtidas atualmente estão condicionadas a herbicidas desenvolvidos recentemente, de baixa toxicidade e de utilização em baixas doses como os herbicidas dos grupos das imidazolinonas e sulfoniluréias, que proporcionam menor impacto para o ambiente (Goldburg, 1992). As CRH podem servir como fonte de resistência e, através do fluxo gênico, proporcionar o surgimento de plantas daninhas resistentes aos herbicidas (Marshall, 1998), o que se caracteriza como uma das desvantagens desta técnica. Entretanto, o manejo correto de herbicidas em relação ao não uso contínuo de um mesmo mecanismo de ação (Vidal, 1997), que deve acontecer em todos os sistemas de controle de plantas daninhas, também deve ser utilizado como um método para evitar este problema quando da utilização das CRH.

As CRH do grupo das sulfoniluréias são desenvolvidas através de introdução gênica proporcionando insensibilidade enzimática (Saari \& Mauvais, 1996), processo este que difere da 
seletividade natural existente nas culturas tolerantes aos inibidores de ALS a qual acontece através da rápida degradação destes herbicidas. (Sherman et al., 1996; Vidal, 1997). Entretanto, a resistência a estes herbicidas também pode ser obtida através de processos tradicionais de seleção de mutantes. A resistência aos herbicidas inibidores de ALS foi conseguida por mutagenese, seguida por seleção com o herbicida chlorsulfuron e isolamento do gene Als1, caracterizando-se esta resistência como monogênica e semidominante (Sebastian \& Chaleff, 1989). No Brasil, realizaram-se trabalhos de introdução do gene Als1 conferindo resistência a sulfoniluréias, tendo como fonte o genótipo Willians 20 que também teve como herbicida para seleção o chlorsulfuron (Vicente et al., 1995), resultando no desenvolvimento da cultivar Coodetec 201.

O objetivo deste trabalho foi avaliar o índice de resistência e a resistência cruzada da cultivar Coodetec 201 a três herbicidas inibidores de ALS não recomendados para a cultura da soja.

\section{MATERIAL E MÉTODOS}

$\mathrm{O}$ experimento foi realizado em casa de vegetação na Faculdade de Agronomia da Universidade Federal do Rio Grande do Sul (UFRGS) em Porto Alegre, RS. A soja foi semeada em meados de agosto de 1997, em vasos com capacidade de $2 \mathrm{~L}$ preenchidos com solo com as seguintes características: argila $=16 \%, \mathrm{pH}=$ 5,$5 ; \mathrm{P}($ Melich $)=39 \mu \mathrm{g} \cdot \mathrm{g}^{-1} ; \mathrm{K}($ Melich $)=$ $87 \mu \mathrm{g} . \mathrm{g}^{-1} ; \mathrm{Al}=0,2 \mathrm{cmol} \cdot \mathrm{dm}^{-3}$ de solo e M.O = $27 \mathrm{~g} . \mathrm{dm}^{-3}$. Na semeadura colocou-se 10 sementes por vaso, e após 10 dias foi realizado desbaste deixando-se apenas duas plantas. Os vasos foram conduzidos com sub irrigação e mantidos em bandejas plásticas com uma lâmina de água de um centímetro.

O delineamento experimental utilizado foi o completamente casualizado em arranjo fatorial com quatro repetições. O primeiro fator constou das cultivares de soja Coodetec 201 e Ocepar 14, o segundo fator consistiu dos herbicidas imazapyr, metsulfuron e nicosulfuron, e o terceiro fator de 5 doses de cada herbicida. As doses referenciais para imazapyr, metsulfuron e nicosulfuron foram de 500, 3,6 e 60 g.ha ${ }^{-1}$, que correspondem, em média, a dose recomendada de cada produto. Na cultivar Ocepar 14, as doses utilizadas foram 0, 5, 10, $40 \mathrm{e}$ $80 \%$ da dose de referência para ambos os herbicidas. Para a cultivar Coodetec 201, utilizouse doses de $0,25,50,100$ e $400 \%$ da dose de referência para os herbicidas metsulfuron e nicosulfuron, e de $0,5,10,40$ e $80 \%$ para o herbicida imazapyr. A determinação das doses foi realizada com base em experimentos preliminares.

Os herbicidas foram aplicados com pulverizador pressurizado com $\mathrm{CO}_{2}$, aos 30 dias após a semeadura quando as plantas de soja estavam no estádio V4. O volume de calda utilizado foi de $2001 . \mathrm{lha}^{-1}$, obtido com bicos leque tipo 8002VS e pressão de $175 \mathrm{kPa}$.

As avaliações realizadas foram fitotoxicidade, área foliar e matéria seca das plantas. A fitotoxicidade foi avaliada visualmente aos 14 e 35 dias após os tratamentos (DAT), através de escala percentual, onde 0 (zero) corresponde a nenhuma injúria demonstrada pelas plantas e 100 à destruição total da cultura. A área foliar foi quantificada pela coleta das plantas aos 35 DAT e medida com o equipamento LI-COR 3100. O peso da matéria seca foi determinada aos 35 DAT pela coleta e secagem das plantas à temperatura de $65{ }^{\circ} \mathrm{C}$. A partir dos dados de matéria seca foi determinado a dose necessária para reduzir o acúmulo de matéria seca em $50 \%$ $\left(\mathrm{MS}_{50}\right)$ e o fator de resistência entre as cultivares avaliadas. A $\mathrm{MS}_{50}$ foi determinada para cada herbicida e cultivar, seguida do cálculo do erro padrão da média. $\mathrm{O}$ fator de resistência foi obtido pela razão entre a $\mathrm{MS}_{50}$ da cultivar Coodetec 201 pela $\mathrm{MS}_{50}$ da cultivar Ocepar 14, e indica a diferença de suscetibilidade entre estas cultivares aos herbicidas avaliados. Os resultados foram analisados através das equações linear e quadrática, utilizando-se a dose do herbicida como fator dependente e a fitotoxicidade, área foliar ou a matéria seca como fator independente. 


\section{RESULTADOS E DISCUSSÃO}

Os sintomas causados pelos herbicidas inibidores de ALS acontecem aproximadamente 15 dias após a aplicação (Vidal, 1997), apresentando inicialmente clorose das folhas jovens, e surgimento posterior de coloração avermelhada nas nervuras da face abaxial, com posterior evolução para necrose das folhas. A expressão destes sintomas permitiu a realização das avaliações de fitotoxicidade que demonstraram efeitos diferentes em relação aos herbicidas e cultivares testados. Na avaliação de fitotoxicidade realizada aos 14 DAT, as cultivares Coodetec 201 e Ocepar 14 apresentaram suscetibilidade semelhante para o herbicida imazapyr (Figura 1a). Por outro lado, o herbicida metsulfuron causou menor fitoxicidade na cultivar Coodetec 201 do que na cultivar Ocepar 14 (Figura 1b). Desta forma, a cultivar Coodetec 201 apresenta maior tolerância ao herbicida metsulfuron, que mesmo em dose quatro vezes superior a recomendada para o controle da maioria das plantas daninhas, apresentou baixa fitotoxicidade à cultura. A tolerância da cultivar Coodetec 201 ao herbicida metsulfuron pode estar relacionada a menor sensibilidade da enzima ALS obtida de parentais que possuem esta característica como forma de resistência aos herbicidas inibidores desta enzima (Sebastian \& Chaleff, 1987; Sebastian et al., 1989).

A fitotoxicidade causada pelo herbicida nicosulfuron aos 14 DAT foi menor na cultivar Coodetec 201 do que na Ocepar 14 (Figura 1c). Entretanto, aos 35 DAT as cultivares avaliadas foram igualmente afetadas por este herbicida (Figura 2c). A diminuição dos efeitos de fitotoxicidade aos 35 DAT pode estar relacionada à recuperação das plantas, principalmente através da emissão de novas folhas sem os sintomas da ação do herbicida. No entanto, a maior tolerância ao herbicida metsulfuron na cultivar Coodetec 201 em relação à Ocepar 14 foi evidenciada também na fitotoxicidade aos 35 DAT (Figura 2b), indicando que na cultivar Coodetec 201 a tolerância se manteve mesmo nas estruturas da planta que se desenvolveram após a aplicação do herbicida. A fitotoxicidade causada por imazapyr (Figura 2a) foi intensificada aos 35 DAT e, da mesma forma como aos 14 DAT, foi semelhante para as cultivares Coodetec 201 e Ocepar 14. O herbicida imazapyr apresenta ação não seletiva (Vidal, 1997), que pode estar condicionada a uma alta afinidade pela enzima ALS, levando a uma grande abrangência dos efeitos deste herbicida. Assim, a insensibilidade a herbicidas inibidores de ALS conseguida pelo isolamento do gene Als1 (Sebastian et al., 1989) pode não ser suficiente para diminuir os efeitos de imazapyr.

A área foliar das plantas, avaliada aos 35 DAT, esteve relacionada com a fitotoxicidade avaliada aos 14 e aos 35 DAT. O herbicida imazapyr foi igualmente fitotóxico para as cultivares Coodetec 201 e Ocepar 14 (Figura 3a). A maior tolerância da cultivar Coodetec 201 ao herbicida metsulfuron também foi demonstrada pela área foliar das plantas. $\mathrm{O}$ incremento da dose de metsulfuron para até $14,4 \mathrm{~g} / \mathrm{ha}$ causou menor diminuição da área foliar na cultivar Coodetec 201 do que na cultivar Ocepar 14, cuja área foliar foi diminuída intensamente já na dose de 1,44 g/ha (Figura 3b). Para o herbicida nicosulfuron, a área foliar das plantas da cultivar Ocepar 14 foi mais afetada pelas doses altas do herbicida do que a cultivar Coodetec 201. Para este herbicida, área foliar de aproximadamente $120 \mathrm{~cm}^{2}$ foi produzida pelas cultivares Ocepar 14 e Coodetec 201 com doses de 48 e $240 \mathrm{~g} / \mathrm{ha}$, respectivamente (Figura $3 \mathrm{c}$ ). A dose de $240 \mathrm{~g} / \mathrm{ha}$ de nicosulfuron representa o quádruplo da maior dose recomendada deste produto, enquanto que $48 \mathrm{~g} / \mathrm{ha}$ é aproximadamente $80 \%$ da maior dose utilizada. Estas diferenças apontam para uma maior tolerência ao herbicida nicosulfuron da cultivar Coodetec 201 em relação a Ocepar 14.

Os efeitos de diminuição de $50 \%$ da matéria seca das plantas permite determinar a dose do herbicida que causa restrição ao crescimento das plantas, sendo descrita como $\mathrm{MS}_{50}$ (O’Donovan et al., 1994). A determinação da $\mathrm{MS}_{50}$ proporciona eficiente comparação entre genótipos com relação à tolerância a herbicidas. 

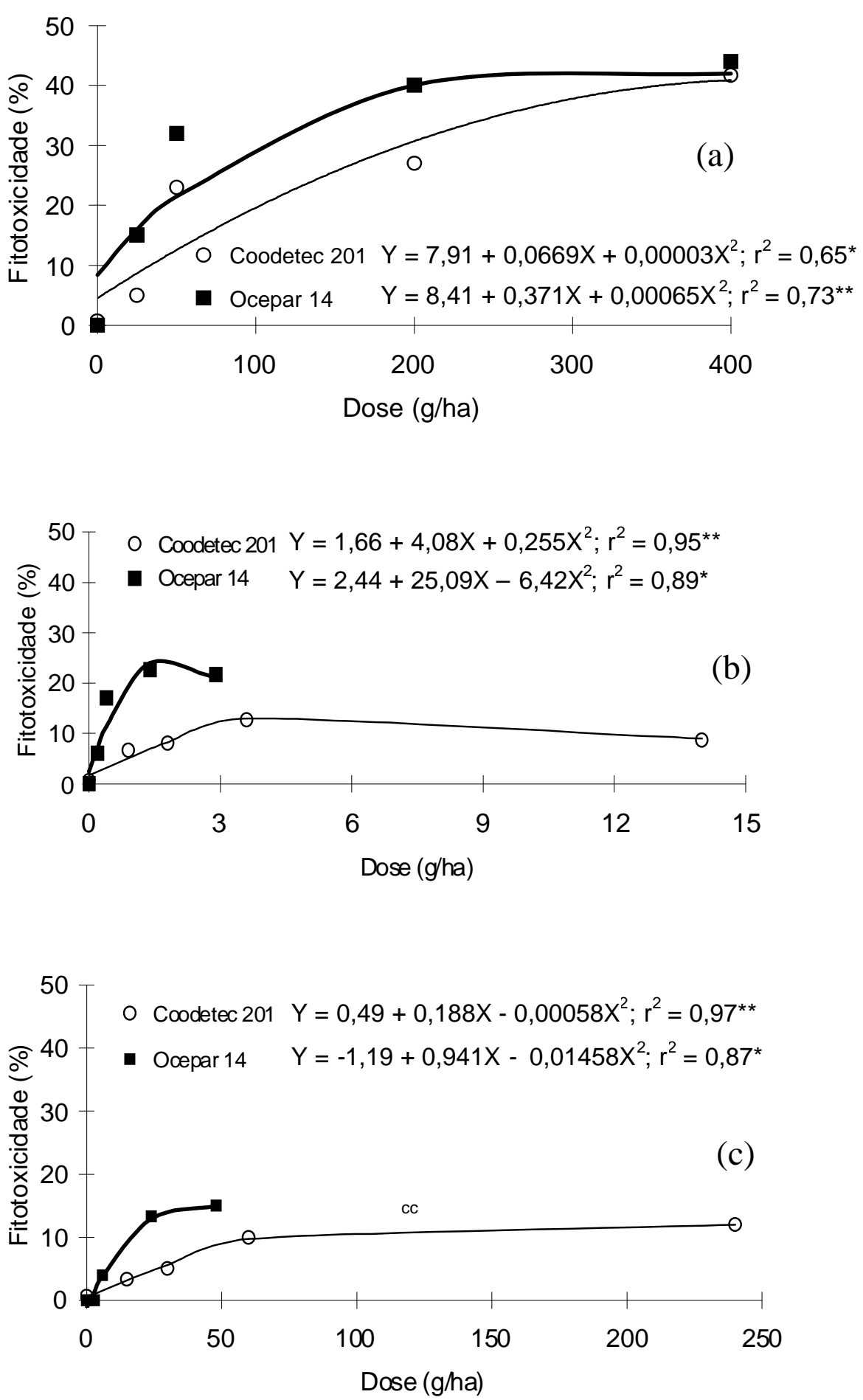

FIGURA 1. Fitoxicidade aos 14 DAT causada pelos herbicidas imazapyr (a), metsulfuron (b) e nicosulfuron (c) nas cultivares de soja Coodetec 201 e Ocepar 14. Porto Alegre (RS), 1997. $(* \mathrm{p}<0,05 ; * * \mathrm{p}<0,01)$. 

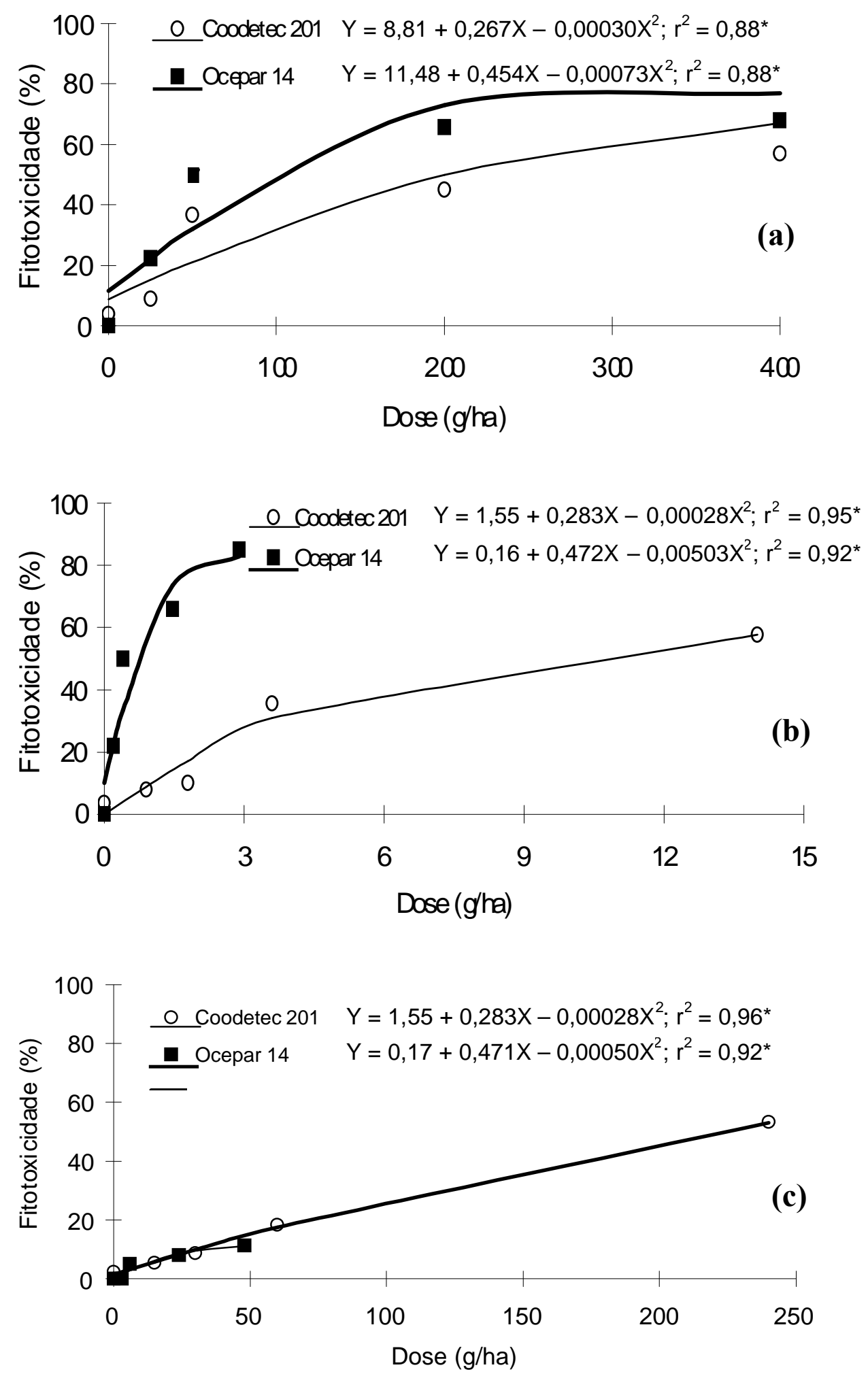

FIGURA 2. Fitotoxicidade aos 35 DAT causada pelos herbicidas imazapyr (a), metsulfuron (b) e nicosulfuron (c) nas cultivares de soja Coodetec 411 e Ocepar 14. Porto Alegre (RS), 1997. (* p < 0,05; ** p < 0,01). 

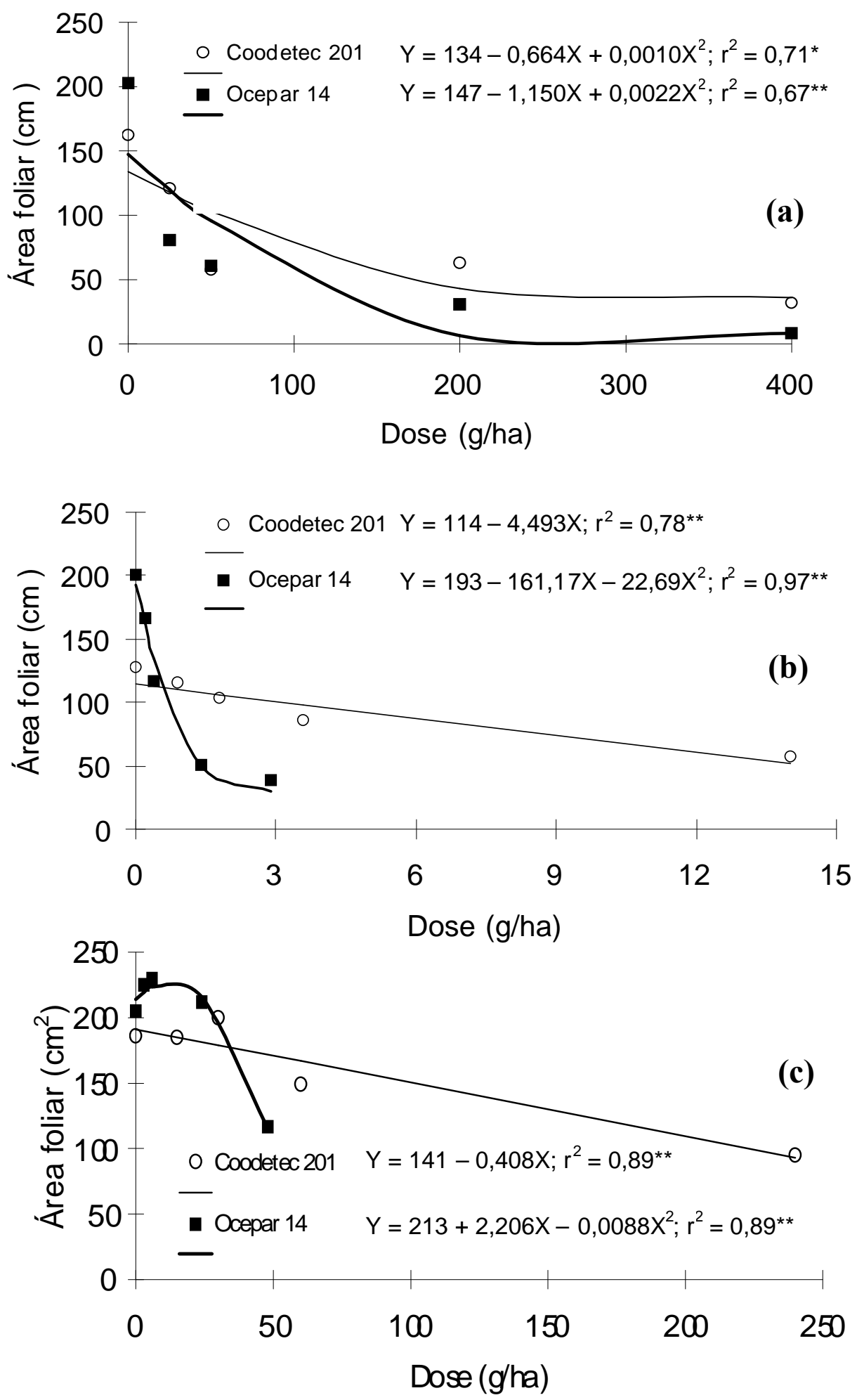

FIGURA 3. Área foliar afetada pelos herbicidas imazapyr (a), metsulfuron (b) e nicosulfuron (c) nas cultivares Coodetec 411 e Ocepar 14. Porto Alegre (RS). 1997. (* $\mathrm{p}<0,05 ; * * \mathrm{p}<0,01)$. 
A $\mathrm{MS}_{50}$ para o herbicida imazapyr, de forma semelhante ao demonstrado nas avaliações de fitotoxicidade e área foliar, indica que as cultivares Coodetec 201 e Ocepar 14 são igualmente sensíveis a este herbicida (Tabela 1). Por outro lado, existem diferenças entre as doses de restrição ao crescimento das plantas de soja nas cultivares Coodetec 201 e Ocepar 14 para os herbicidas metsulfuron e nicosulfuron. Estas diferenças são demonstradas pelo fator de resistência, onde se observa que a cultivar Coodetec 201 é 10,25 vezes mais tolerante ao herbicida metsulfuron do que a cultivar Ocepar 14, enquanto que para o herbicida nicosulfuron esta relação é de 3,25 vezes (Tabela 1).

TABELA 1. Doses necessária para reduzir a matéria seca em $50 \%\left(\mathrm{MS}_{50}\right)$ e fatores de resistência obtidos com a utilização de três herbicidas inibidores de ALS nas cultivares de soja Coodetec $201 \mathrm{e}$ Ocepar 14. Porto Alegre (RS), 1997.

\begin{tabular}{lccc}
\hline Herbicida & \multicolumn{2}{c}{ Índice de inibição $\left(\mathrm{MS}_{50}\right)$} & Fator de resistência $^{1}$ \\
\cline { 2 - 3 } & Coodetec 201 & Ocepar 14 & \\
\hline Imazapyr & $125,0 \pm 80,0^{2}$ & $44,0 \pm 24,0$ & $\mathrm{~ns}^{3}$ \\
Metsulfuron & $12,3 \pm 5,4$ & $1,2 \pm 0,3$ & 10,25 \\
Nicosulfuron & $195,0 \pm 21,0$ & $60,0 \pm 10,5$ & 3,25 \\
\hline
\end{tabular}

${ }^{1}$ Razão do índice de inibição da cultivar Coodetec 201 pela Ocepar 14.

${ }^{2}$ Acréscimo ou redução média da dose necesssária para alterar a matéria seca na faixa equivalente ao erro padrão.

${ }^{3}$ Não significativo a $5 \%$ de significância.

Existe grande variação do nível de resistência em genótipos tolerantes aos diferentes herbicidas do grupo das sulfoniluréias (Menendez et al., 1994), o que pode ser devido às diferenças na estrutura química dos compostos e à variação da causa pela qual a resistência ao herbicida é alcançada. Com relação ao efeito da estrutura química dos compostos, salienta-se que a seleção dos mutantes de soja que resultaram no genótipo parental resistente foi realizada com o herbicida chlorsulfuron (Sebastian et al., 1989). Neste caso, o fator de resistência da cultivar tolerante em relação à população original foi de até 100 vezes, demonstrando a alta eficiência da mutação na tolerância a este herbicida. Assim, a magnitude da tolerância a outros herbicidas inibidores de ALS pode estar condicionada à semelhança estrutural destes com o herbicida clorsulfuron.

A resistência cruzada aos herbicidas é caracterizada quando se obtém resistência a outros herbicidas diferentes daquele utilizado na seleção dos mutantes. Em soja, Sebastian et al.(1989) obtiveram resistência cruzada ao herbida chlorimuron etil com uma tolerância 10 vezes superior ao genótipo sensível. Entretanto, não foi encontrado resistência cruzada a outros herbicidas sulfoniluréias nas culturas de fumo e beterraba açucareira (Saari \& Mauvais, 1996). Os níveis de resistência obtidos para a cultivar Coodetec 201 indicam que existe resistência cruzada nesta cultivar. As doses de tolerância são suficientes para o controle da maioria das plantas daninhas às quais estes herbicidas são utilizados. Entretanto, a utilização destes herbicidas na cultivar de soja Coodetec 201 depende de maiores determinações sobre o crescimento e desenvolvimento da cultura, e também na qualidade e no rendimento de grãos. 


\section{LITERATURA CITADA}

COLE, D. J. Detoxification and activation of agrochemicals in plants. Pestic. Sci., v. 42, n. 3, p. 209-222, 1994.

DUKE, S. O. Herbicide resistant crops Background and perspectives. In: DUKE, S. O., ed. Herbicide-resistant crops. Boca Raton: CRC Press, 1996. p. 1-12.

GOLDBURG R. J. Environment concerns with the development of herbicide-resistant crops. Weed Technol., v. 6, n. 3, p. 647-653, 1992.

KISHORE, G. M.; PADGETTE, S. R.; FRALEY, R. T. History of herbicide-tolerant crops, methods of development and current state of the art - Enphasis on glyphosate tolerance. Weed Technol., v. 6, n. 3, p. 626-634, 1992.

KRAUSZ, R. F.; KAPUSTA, G.; MATTHEWS, J.

L. Acetolactate synthase-resistant and susceptible corn (Zea mays) response to imazethapyr, imazaquin, chlorimuron, and CGA-152005. Weed Technol., v. 11, n. 4, p. 810-816, 1997.

MARSHALL, G. Tolerant crops - real farmer opportunity of potential environmental problem ?. Pestic. Sci., v. 52, n. 4, p. $394-$ 402, 1998.

MENENDEZ, J.; JORRIN, J.; ROMERA, E.; PRADO, R. Resistance to chlortoluron of a slender foxtail (Alopecurus myosuroides) biotype. Weed Sci., v. 42, p. 340-344, 1994.

O'DONOVAN, J. T.; SHARMA, M. P.; HARKER, K. N.; MAURICE, D.; BAIG, N. M.; BLAKSHAW, R. E. Wild oat (Avena fatua) populations resistant to triallate are also resistant do difenzoquat. Weed Sci., v. 42, n. 2, p. 195-199, 1994.

RADOSEVICH, S. R.; GHERSA, C. M.; COMSTOCK, G. Concerns a weed scientist might have about herbicide-tolerant crops. Weed Technol., v 6, n. 3, p. 635-639, 1992.

SAARI, L. L., MAUVAIS, C. J. Sulfonylurea herbicide-resistant crops. In: DUKE, S. O., ed. Herbicide-resistant crops. Boca Raton: CRC Press, 1996. p. 127-142.

SEBASTIAN, S. A.; FADER, G. M.; ULRICH, J. F.; FORNEY, D. R.; CHALEFF, R. S. Semidominant soybean mutation for resistance to sulfonylurea herbicides. Crop Sci., v. 29, n. 6, p. 1403-1408, 1989.

SEBASTIAN, S. A.; CHALEFF, R. S. Soybean mutants with increased tolerance for sulfonylurea herbicides. Crop Sci., v. 27, n. 5, p. 948-952, 1987.

SHERMAN, T. D.; VAUGHN K. C., DUKE, S. O. Mechanisms of action and resistence to herbicides. In: DUKE, S. O., ed. Herbicideresistant crops. Boca Raton, CRC Press, 1996. p. 13-36.

SIMPSON, D. M.; STOLLER, E.W. Thinfensulfuron and imazethapyr interaction at the ALS enzyme in sulfonylurea-tolerant soybean (Glycine max). Weed Sci., v. 44, n. 4, p. 763-768, 1996.

VICENTE, D.; HARADA, A.; HIDALGO, E. Obtenção de linhagens de soja (Glycine max) com maior tolerância aos herbicidas do grupo das sulfoniluréis. In: CONGRESSO BRASILEIRO DA CIÊNCIA DAS PLANTAS DANINHAS, 20, Florianópolis, SC. Resumos... Florianópolis, p. 424-425, 1995. 
VIDAL, R. A. Herbicidas: Mecanismo de ação e resistência de plantas. Porto Alegre, Ribas Vidal, 1997, $165 \mathrm{p}$.

WILCUT, J. W.; COBLE, H. D.; YORK, A. C.; MONKS, D. W. The niche for herbicideresistant crops in U.S. agriculture. In: DUKE, S. O., ed. Herbicide-resistant crops. Boca Raton: CRC Press, 1996. p. 213-230.

WRIGHT, T. R.; PENNER, D. Corn (Zea mays) acetolactate synthase sensitivity to four classes of ALS-inhibiting herbicides. Weed Sci., v. 46, n.1, p. 8-12. 1998. 